\title{
A Call for Canadian Pediatric Emergency Guidelines- As Certain As Motherhood?
}

\author{
Jeff Freeman, MD; Sara Ahmed, MD
}

In this issue of CFEM, Hamid and colleagues present a cogent argument for the development of Canadian guidelines for emergency departments (EDs) that recognize the unique needs of pediatric patients. ${ }^{1}$ Like "motherhood and apple pie," this seems like a self-evident issue that appeals to the broad belief in the protection and prosperity of our next generation. While their call for guidelines is compelling and exhilarating, it is prudent to question a few of the assumptions of this paper:

1. Do guidelines really need to be customized for Canada?

2. How do we ensure the guidelines will be evidencebased and free of influence?

3. Will having such guidelines result in a positive impact on pediatric care?

4. What are the most cost-effective priorities?

5. Should this take precedence over other health care priorities?

Most would agree in principle with a process of standardizing and improving the care of children in EDs. It is still unclear whether a Canadian-specific guideline is even needed. The International Federation for Emergency Medicine (IFEM) guidelines referred to by the authors could be the launching tool that each organization uses in their own advancement. The IFEM guidelines are sufficiently inclusive to allow modification at the institutional level based on its needs.

It may be challenging for individual institutions to discover their particular needs. We require a systematic way to evaluate the existing conditions, recognize our weaknesses, initiate improvements, and measure our success. This is all currently taking place, albeit slowly, through the TREKK (TRanslating Emergency
Knowledge for Kids) initiative: "37 general emergency departments across Canada (urban, rural and remote), spanning nine provinces and one territory." 2 The process the authors are calling for already exists in Canada without having national guidelines.

The other problem with national guidelines is their tendency to be based on opinion and clinical judgment, rather than unbiased scientific evidence. Too many guidelines are birthed through the expert wisdom of "GOBSAT" (Good Old Boys Sat Around a Table). ${ }^{3}$ We should be cautious that guidelines are transparently developed based on best evidence and do not reflect only the advocacy of the interested parties.

Unfortunately, the decade-long delay in knowledge translation often means that guidelines alone are insufficient to change practice. (Multiple guidelines published in the past 20 years reflect on the complexity and effectiveness of pursuing change through guidelines.) $)^{4}$ Deployment and implementation of guidelines require more than good evidence to guarantee success. ${ }^{5}$ Guidelines frequently have no timely impact on practice. Guideline authors must propose an action plan for the promulgation and enactment of their recommendations. One such action plan is the National Pediatric Readiness project, where each hospital can score their current status and decide locally where they want to make changes, depending on their resources. ${ }^{6}$ Their project checklist provides a simple comprehensive evaluation of a department's preparedness for pediatric emergency care. ${ }^{7}$

Each community ED must begin by considering both the importance and the cost of each priority. For example, Hamid and colleagues call for application of pediatric triage tools and pain scales, both low-cost initiatives. Once equal education and basic standards of care have been established for pediatric care, then a separate waiting area and

From the *Faculty of Medicine, University of Ottawa, Ottawa, ON; and TMary Bridge Children's Hospital, Tacoma, WA, United States.

Correspondence to: Dr. Jeffrey Freeman, Department of Emergency Medicine, 1053 Carling Ave., E-Main Room EM-206, Box 227, Ottawa, ON K1Y 4E9; Email: jfreeman@toh.on.ca 
evaluation area would be ideal. There is a cost to a department to do this but it is a service to their community. A happy child will look less anxious, which leads to a decreased work-up, and therefore less money spent on evaluation and a decreased length of stay. ${ }^{8}$

In contrast, a shared trauma bay is more cost efficient and can lead to improved outcomes. ${ }^{9}$ The cost is decreased because advanced airway tools, ultrasound machines, and other resuscitation equipment do not need to be duplicated. The nurses who work in a trauma bay will have more experience in medical and trauma resuscitations, and they simply may need to add training, such as pediatric advanced life support (PALS) and pediatric sepsis guidelines to their knowledge base. Training needs are ever-evolving and continuous. The hard reality is that training and departmental changes may require substantial and ongoing costs and effort.

Finally, from a sweeping perspective, while this call for guidelines seems fundamental, inspiring and vital, no emphasis comes without consequence. Some would argue that our EDs need more effort in being prepared for geriatric care (where outcomes are obviously much worse), or sepsis care, or palliative care, or a myriad of other areas where health care loyalties have focused. Children should have pleasant, low-stress visits to safe and efficient EDs. The demand for limited health care dollars requires more evidence before this becomes a national focus and priority.
Keywords: Pediatric, Emergency Department, Guidelines, Canadian, Children

Competing interests: None declared.

\section{REFERENCES}

1. Hamid MA, Siddiqui S, Chandna A, et al. Children are not young adults: a call for standardized guidelines for dealing with pediatric patients in the emergency department of Canadian community hospitals. CFEM 2015; epub, 1-4, doi: 10.1017/cem.2015.45.

2. Translating Emergency Knowledge for Kids (TREKK). Available at: http://trekk.ca/ (accessed 20 February 2015).

3. Miller J, Petrie J. Development of practice guidelines. Lancet 2000;355(9198):82-3.

4. Registered Nurses' Association of Ontario. Toolkit: Implementation of best practice guidelines, 2 nd ed. Toronto, ON: Registered Nurses' Association of Ontario; 2012.

5. Shaneyfelt T, Centor R. Reassessment of clinical practice guidelines: go gently into that good night. FAMA 2009;301 (8):868-9, doi: 10.1001/jama.2009.225.

6. National Pediatric Readiness Project. Available at: http:// www.pediatricreadiness.org/ (accessed 8 February 2015).

7. Guidelines for Care of Children in the Emergency Department. Available at: http://www.pediatricreadiness. org/files/PDF/Checklist.pdf (accessed 8 February 2015).

8. Kim BB, Delbridge TR, Kendrick DB. Improving process quality for pediatric emergency department. Int 7 Health Care Qual Assur 2014;27(4):336-46.

9. Oyetunji TA, Haider AH, Downing SR, et al. Treatment outcomes of injured children at adult level 1 trauma centers: are there benefits from added specialized care? Am 7 Surg 2011;201(4):445-9, doi: 10.1016/j.amjsurg.2010.10.006. 